\title{
Article \\ Early Enriched Environment Prevents Epigenetic p11 Gene Changes Induced by Adulthood Stress in Mice
}

\author{
Mi Kyoung Seo ${ }^{1}$, Ah Jeong Choi ${ }^{2}$, Dae-Hyun Seog ${ }^{3,4}$, Jung Goo Lee ${ }^{1,5,6, *(\mathbb{C})}$ and Sung Woo Park ${ }^{1,6,7, * \mathbb{C}}$ \\ 1 Paik Institute for Clinical Research, Inje University, Busan 47392, Korea; banaba66@inje.ac.kr \\ Sumagen, Seoul 06159, Korea; dkwjd2675@naver.com \\ Department of Biochemistry, College of Medicine, Inje University, Busan 47392, Korea; daehyun@inje.ac.kr \\ Dementia and Neurodegenerative Disease Research Center, Inje University, Busan 47392, Korea \\ Department of Psychiatry, College of Medicine, Haeundae Paik Hospital, Inje University, Busan 48108, Korea \\ Department of Health Science and Technology, Graduate School, Inje University, Busan 47392, Korea \\ 7 Department of Convergence Biomedical Science, College of Medicine, Inje University, Busan 47392, Korea \\ * Correspondence: iybihwc@inje.ac.kr (J.G.L.); swpark@inje.ac.kr (S.W.P.); Tel.: +82-51-797-3300 (J.G.L.); \\ +82-51-890-6071 (S.W.P.); Fax: +82-51-894-6709 (J.G.L. \& S.W.P.)
}

Citation: Seo, M.K.; Choi, A.J.; Seog, D.-H.; Lee, J.G.; Park, S.W. Early Enriched Environment Prevents Epigenetic p11 Gene Changes Induced by Adulthood Stress in Mice. Int. J. Mol. Sci. 2021, 22, 1928. https://doi.org/10.3390/ijms22041928

Academic Editor: Yong-Ku Kim

Received: 22 January 2021

Accepted: 12 February 2021

Published: 15 February 2021

Publisher's Note: MDPI stays neutral with regard to jurisdictional claims in published maps and institutional affiliations.

Copyright: (c) 2021 by the authors. Licensee MDPI, Basel, Switzerland. This article is an open access article distributed under the terms and conditions of the Creative Commons Attribution (CC BY) license (https:// creativecommons.org/licenses/by/ $4.0 /)$.

\begin{abstract}
Positive experiences in early life may improve the capacity to cope with adulthood stress through epigenetic modification. We investigated whether an enriched environment (EE) in the postnatal period affected epigenetic changes in the $\mathrm{p} 11$ gene induced by chronic unpredictable stress (CUS) in adult C57BL/6 J mice. EE was introduced for 5 weeks during postnatal days 21-55. After $\mathrm{EE}$, the mice were subjected to CUS for 4 weeks. EE prevented depression-like behavior induced by adult CUS. EE prevented a decrease in p11 mRNA and histone $\mathrm{H} 3$ acetylation induced by CUS, with changes in the expression of histone deacetylase 5. Moreover, EE prevented changes in trimethylation of histone H3 lysine 4 (H3K4) and H3K27 induced by CUS. Furthermore, EE had positive effects on behavior and epigenetic alterations in adult mice without CUS. These results suggest that one of the underlying mechanisms of early-life EE may involve epigenetic modification of the hippocampal p11 gene promoter.
\end{abstract}

Keywords: chronic unpredictable stress; depression; early enriched environment; epigenetic mechanism; p11

\section{Introduction}

Human responses to stress vary among individuals. Some people develop stressrelated psychiatric disorders such as depression, others develop mild to moderate psychiatric symptoms that recover quickly, and still others report no symptoms in response to stress [1,2]. Interindividual difference in vulnerability and resilience to stress may depend on early life experiences. Positive experiences in early life may improve the capacity to cope with adulthood stress through epigenetic modification. Numerous studies have indicated that adverse experiences in early life augment the risk of depression in adulthood and that this effect is influenced by epigenetic mechanisms [3-5]. Compared to numerous studies on long-term effects of negative experiences in early life, there is limited research on the effect of positive experiences in early life. In rodents, high levels of maternal care exhibited long-term effects on the epigenomic state, brain function, and behavior of offspring [6,7].

Posttranslational modification of histones (i.e., histone acetylation and methylation), a well-studied epigenetic mechanism, is a process that controls gene activation or silencing by altering the chromatin structure and compaction in the promoter regions of particular genes [8,9]. Histone acetylation ( $\mathrm{H} 3$ and $\mathrm{H} 4$ acetylation) relaxes the interaction between DNA and histone, allowing the transcriptional machinery to bind to the promoters of particular genes, thereby activating transcription $[8,9]$. Coactivator complexes needed for transcriptional activation have histone acetyltransferases (HATs), whereas 
transcriptional corepressor complexes have histone deacetylases (HDACs) [10,11]. Histone methylation, on the other hand, can influence both transcriptional activation (H3K4 and $\mathrm{H} 3 \mathrm{~K} 36)$ and repression (H3K9, H3K27, and H3K20), depending on the lysine (K) residue of the histone tail as well as the valence state of the methylation (mono-, di-, or trimethylation) [12,13].

Expression of p11, also called S100A10, plays a critical role in depression-like behaviors and responses to antidepressant drugs [14]. For example, p11 expression was decreased in the brains of humans with depression and in mouse models of depression, and it was increased by treatment with antidepressant drugs [15]. Moreover, p11 knockout mice exhibited depression-like behaviors, and transgenic mice overexpressing p11 exhibited antidepressant-like effects $[15,16]$. Furthermore, p11 expression is regulated by brain-derived neurotropic factor (BDNF), which plays important roles in neural plasticity and neurogenesis in the hippocampus, and the antidepressant-like effects of BDNF depend on p11 [17].

An enriched environment (EE) is the manipulation of standard laboratory conditions to reach optimization of the breeding environment by modifying the quality and intensity of environmental stimuli. EE is also known to have a significant effect on the central nervous system (CNS) at a functional, anatomical, and molecular level both in the critical period of development and in adulthood [18]. It is known that EE has an effect on neural plasticity of the brain and the possibility of it becoming a new target for the treatment of neurological and mental disorders has been suggested [19]. In general, in animal experiments, EE comprises housing conditions that provide sensory, cognitive, and motor stimulation [20]. EE treatment enhanced neurogenesis and synaptic plasticity and increased BDNF expression in the hippocampus [21]. In rats, EE exposure after weaning reduced adult anxiety-like behavior [22] and influenced hippocampal gene expression $[23,24]$. In particular, EE in rats was effective in protecting from the negative effects of stressors [22,25]. These studies highlight the antidepressant effects of EE. In this study, we focused on the long-term effects of early-life EE on resilience under adulthood stress. Therefore, we investigated whether early EE after weaning can induce long-lasting effects on depression-like behavior induced by adulthood stress and whether the effects of EE are involved in epigenetic modification of the p11 gene. According to "neurotrophic hypothesis of depression", stress-induced changes in hippocampal gene expression are known to play an important role in the pathophysiology of depression [26,27]. EE improves the neural plasticity of the hippocampus. Thus, we examined the molecular levels in the hippocampus. We employed chronic unpredictable stress (CUS), an animal model of depression, as a form of adult stress.

\section{Results}

\subsection{Effects of EE and CUS on Depression-Like Behavior and Plasma Corticosterone Levels}

The experimental design is shown in Figure 1. First, we examined the effects of CUS on depression-like behavior and corticosterone levels in mice housed under standard or EE conditions during early life (Figure 2).

Immobility times during the forced swimming test (FST) $(n=4-6$ animals per group) are presented in Figure 2A. Two-way ANOVA revealed the following values: $\mathrm{EE} F_{(1,15)}=7.158$, $p=0.017$; CUS $F_{(1,15)}=33.889, p<0.001 ; \mathrm{EE} \times$ CUS interaction $F_{(4,53)}=33.889, p<0.001$. Post hoc comparisons showed that CUS-exposed mice exhibited a significant depression-like phenotype compared to controls ( $90.3 \pm 9.7$ vs. $137.3 \pm 14.4 \mathrm{~s}, p=0.040)$. However, exposure to EE significantly decreased the immobility time in CUS-treated mice (137.3 \pm 14.4 vs. $33.1 \pm 12.0 \mathrm{~s}, p<0.001$ ), suggesting that early-life EE prevented depression-like behavior induced by CUS in adult mice. Moreover, EE mice displayed reduced immobility time compared to controls ( $90.3 \pm 9.7$ vs. $40.2 \pm 4.4 \mathrm{~s}, p=0.010)$, showing that treatment with EE alone during early life had an antidepressant effect in adulthood. 


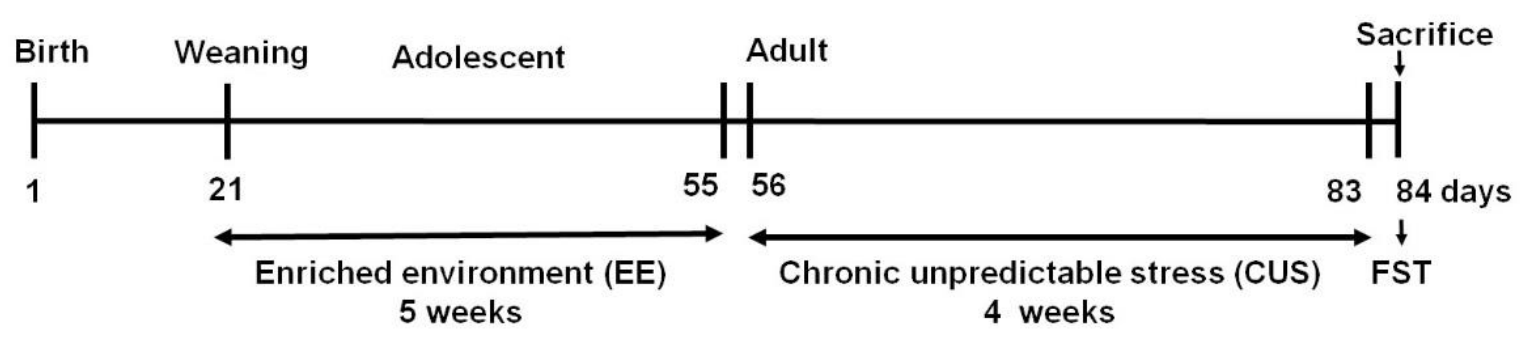

Experimental Groups

Control group; non-EE, non-CUS mice

EE group; EE, non-CUS mice

CUS group; non-EE, CUS mice

EE + CUS group; EE, CUS mice

Figure 1. Experimental design. The mice pups were exposed to an enriched environment (EE) for 5 weeks during the post-weaning period. When the pups became adults (8 weeks of age), they were subjected to chronic unpredictable stress (CUS) for 4 weeks. Twenty-four hours after the last CUS protocol, the mice were exposed to the forced swimming test (FST). The mice were sacrificed immediately after FST.

(A)

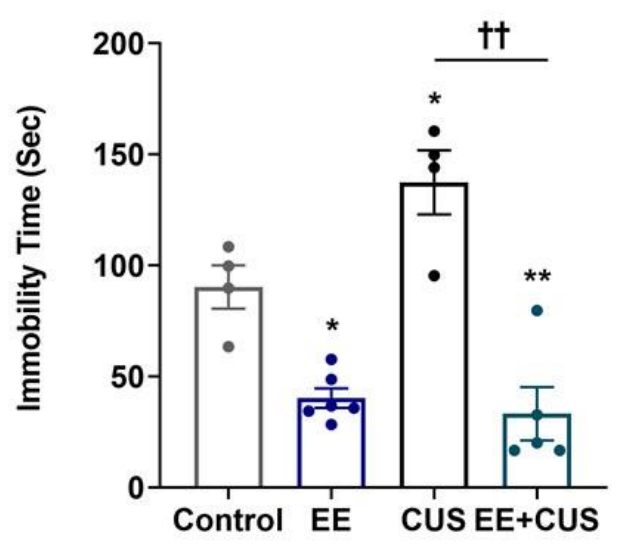

(B)

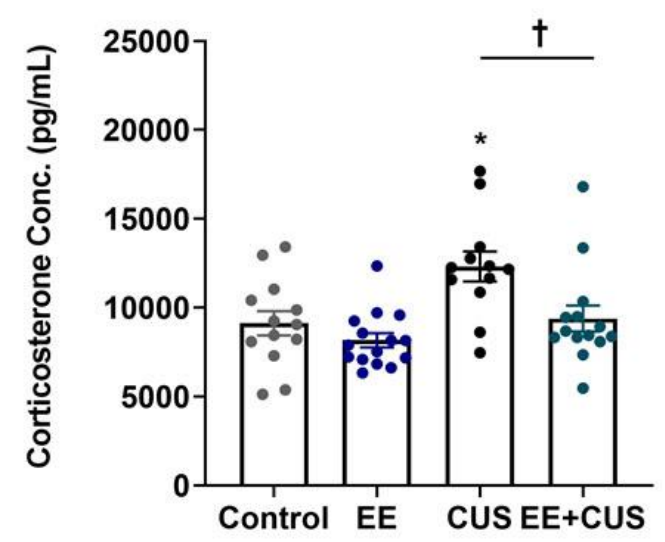

Figure 2. Effects of EE and CUS on depression-like behavior and plasma corticosterone levels. (A) Immobility time in the FST was measured at $24 \mathrm{~h}$ after the last CUS cession; $n=4-6$ animals/group. (B) Corticosterone levels were measured using an enzyme-linked immunosorbent assay kit; $n=12-15$ animals/group. Data are presented as mean \pm SEM. ${ }^{*} p<0.05$ vs. control group; ${ }^{* *} p<0.01$ vs. control group; $\dagger p<0.05$ vs. CUS group; $+\dagger p<0.01$ vs. CUS group.

Figure 2B shows the effects of EE and CUS on plasma corticosterone levels $(n=12-15$ animals per group). Two-way ANOVA revealed significant effects of EE: $F_{(1,50)}=8.463, p=0.005$; and CUS, $F_{(1,50)}=10.960, p=0.002$; but no $E E \times$ CUS interaction effect, $F_{(1,50)}=2.177, p=0.146$. CUS exposure led to a significant increase in corticosterone levels compared to control conditions (9120 \pm 692 vs. $12,317 \pm 836 \mathrm{pg} / \mathrm{mL}, p=0.010)$, and exposure to EE prevented the CUS-induced increase in corticosterone level (12,317 \pm 836 vs. $9388 \pm 733$ pg $/ \mathrm{mL}, p=0.020)$.

\subsection{Effects of EE and CUS on Hippocampal p11 mRNA Levels}

The effect of EE and CUS on p11 mRNA levels in the hippocampus was determined by qRT-PCR, as shown in Figure 3 ( $n=12-15$ animals per group). Two-way ANOVA revealed significant effects of EE: $F_{(1,50)}=30.300, p<0.001$; CUS $F_{(1,50)}=88.110, p<0.001$; and the $\mathrm{EE} \times \mathrm{CUS}$ interaction $F_{(1,50)}=7.464, p=0.009$. Post hoc analysis revealed a significant decrease in p11 mRNA levels in CUS-exposed mice compared to control mice (100 $\pm 8 \%$ vs. $39 \pm 3 \%, p<0.001)$, whereas early-life EE prevented this reduction $(39 \pm 3 \% \mathrm{vs} .74 \pm 3 \%$, 
$p=0.003)$. Additionally, the 11 mRNA level was 39\% higher in EE-exposed mice compared with control animals $(100 \pm 8 \%$ vs. $139 \pm 9 \%, p<0.001)$.

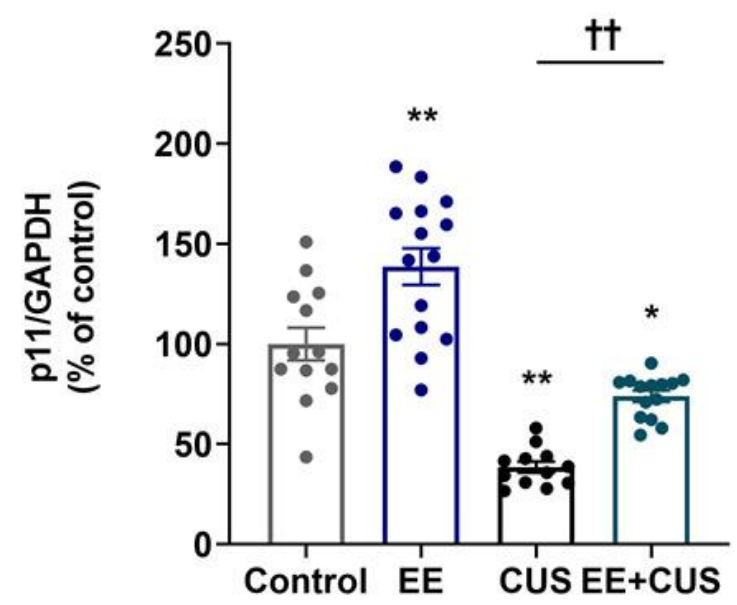

Figure 3. Effects of EE and CUS on hippocampal p11 mRNA levels. The p11 mRNA level in the hippocampus was measured by qRT-PCR. All quantities were normalized to glyceraldehyde-3-phosphate dehydrogenase (GAPDH). Data are expressed as values relative to the control group using the $2^{-\Delta \Delta \mathrm{ct}}$ method. Data represent mean \pm SEM expressed as a percentage of the control group. ${ }^{*} p<0.05$ vs. control group; ${ }^{* *} p<0.01$ vs. control group; ${ }^{+\dagger} p<0.01$ vs. CUS group. $n=12-15$ animals/group.

\subsection{Effects of EE and CUS on the Epigenetic State of the 111 Gene}

We next evaluated whether postnatal exposure to EE induced histone modification that led to activation or repression of the p11 gene. We examined two active histone modifications (acetylation of histone $\mathrm{H} 3$, AcH3; trimethylation of $\mathrm{H} 3 \mathrm{~K} 4, \mathrm{H} 3 \mathrm{~K} 4 \mathrm{me} 3$ ) and one repressive histone modification (trimethylation of H3K27, H3K27me3) in the p11 promoter region in the hippocampus ( $n=12-15$ animals per group).

Two-way ANOVA on AcH3 levels (Figure 4A) revealed significant effects of EE: $F_{(1,50)}=57.530, p<0.001 ; \operatorname{CUS} F_{(1,50)}=16.980, p<0.001$; and the EE $\times$ CUS interaction $F_{(1,50)}=3.099, p=0.084$. CUS reduced the AcH3 level at the $\mathrm{p} 11$ promoter compared to the control condition ( $100 \pm 11 \%$ vs. $60 \pm 3 \%, p=0.037)$, whereas EE increased this level in CUS mice ( $60 \pm 3 \%$ vs. $134 \pm 6 \%, p=0.018)$. EE alone significantly increased $\mathrm{AcH} 3$ compared to control mice $(100 \pm 11 \%$ vs. $174 \pm 14 \%, p<0.001)$. Then, we further examined whether the candidate enzyme HDAC5 was associated with histone acetylation changes observed in the hippocampus. Two-way ANOVA on HDAC5 mRNA levels (Figure 4B) revealed the following values: $E E F_{(1,50)}=41.830$, $p<0.001$; CUS $F_{(1,50)}=254.900, p<0.001$; and the EE $\times$ CUS interaction $F_{(1,50)}=4.585$, $p=0.037$. Post hoc analysis showed that HDAC5 mRNA levels were $335 \%$ higher in the hippocampus of CUS-exposed mice compared with control animals (100 $\pm 5 \%$ vs. $335 \pm 17 \%, p<0.001$ ), whereas EE exposure prevented this effect of CUS on HDAC5 expression ( $335 \pm 17 \%$ vs. $223 \pm 19 \%, p<0.001$ ). Moreover, EE decreased hippocampal HDAC5 expression compared to control conditions ( $100 \pm 5 \%$ vs. $44 \pm 3 \%, p=0.015)$.

Two-way ANOVA on H3K4me3 levels (Figure $5 \mathrm{~A}$ ) revealed the following values: EE $F_{(1,50)}=27.860, p<0.001$; CUS $F_{(1,50)}=21.130, p<0.001$; and the EE $\times$ CUS interaction $F_{(1,50)}=0.161, p=0.690$. Exposure to CUS induced a significant decrease in the H3K4me3 level compared to control mice (100 $\pm 9 \%$ vs. $50 \pm 6 \%, p=0.007)$, and EE restored the H3K4me3 level at the $\mathrm{p} 11$ promoter in the hippocampus of CUS-exposed animals to normal levels ( $50 \pm 6 \%$ vs. $107 \pm 11 \%, p=0.017$ ). A significant difference in the H3K4me3 level was observed between control and EE-exposed animals (100 $\pm 9 \%$ vs. $149 \pm 12 \%, p=0.005$ ). 
(A)

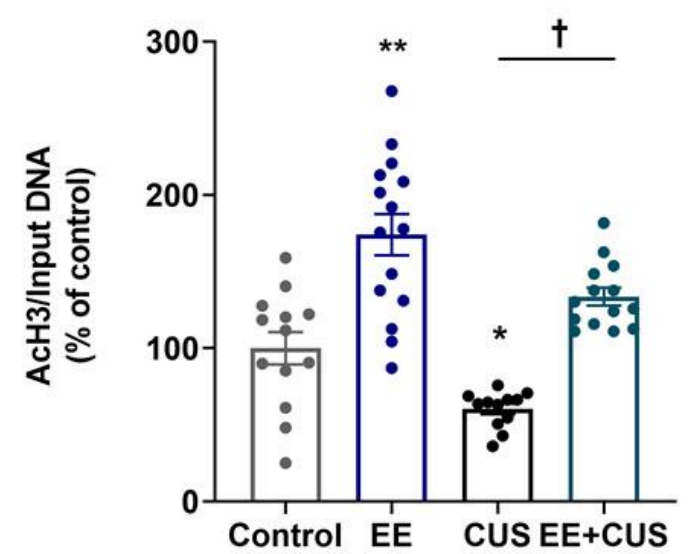

(B)

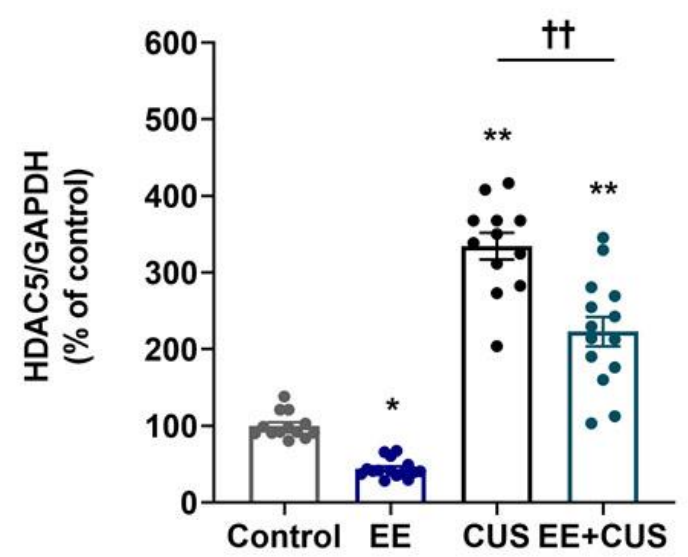

Figure 4. Effects of EE and CUS on the level of histone $\mathrm{H3}$ acetylation at the p11 promoter and HDAC5 expression in the hippocampus. (A) Chromatin immunoprecipitation (ChIP) assays were performed to measure the level of acetylated histone $\mathrm{H} 3$ (AcH3) at the p11 promoter in the hippocampus using an antibody to AcH3. Data were normalized to input DNA. (B) The HDAC5 mRNA level in the hippocampus was measured by qRT-PCR. All quantities were normalized to GAPDH. Data are expressed as values relative to the control group using the $2^{-\Delta \Delta \mathrm{ct}}$ method. Data represent mean \pm SEM expressed as a percentage of the control group. ${ }^{*} p<0.05$ vs. control group; ${ }^{* *} p<0.01$ vs. control group; ${ }^{\dagger} p<0.05$ vs. CUS group; ${ }^{\dagger+} p<0.01$ vs. CUS group. $n=12-15$ animals/group.

(A)

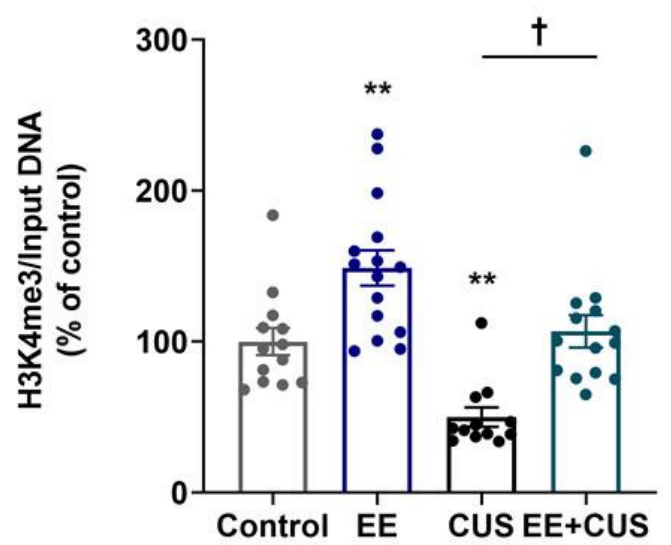

(B)

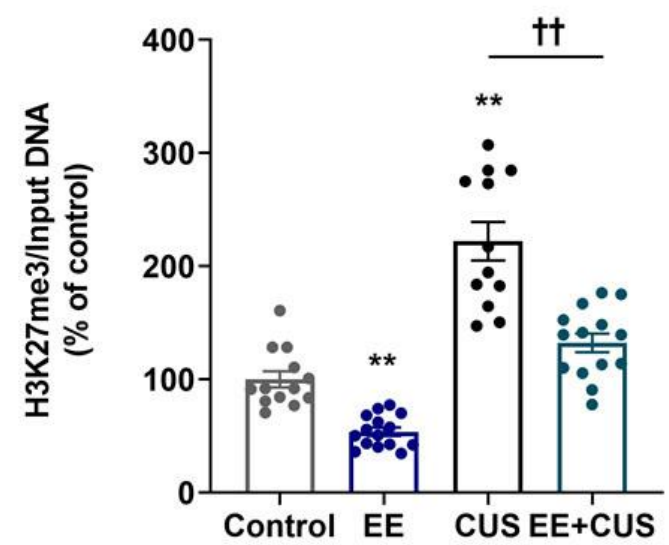

Figure 5. Effects of EE and CUS on the levels of histone $\mathrm{H} 3$ methylation at the p11 promoter in the hippocampus. The levels of histone $\mathrm{H} 3$ trimethylated K4 (H3K4me3, (A)) and K27 (H3K27me3, (B)) at the p11 promoter in the hippocampus were measured by ChIP assay using antibodies to H3K4me3 and H3K27me3. Data were normalized to input DNA and are expressed as values relative to the control group using the $2^{-\Delta \Delta c t}$ method. Data represent mean \pm SEM expressed as a percentage of the control group. ${ }^{* *} p<0.01$ vs. control group; ${ }^{\dagger} p<0.05$ vs. CUS group; ${ }^{+\dagger} p<0.01$ vs. CUS group. $n=12-15$ animals/group.

Two-way ANOVA on H3K27me3 levels (Figure 5B) revealed the following values: EE $F_{(1,50)}=50.590, p<0.001$; CUS $F_{(1,50)}=109.700, p<0.001$; and the EE $\times$ CUS interaction $F_{(1,50)}=5.181, p=0.027$. The level of H3K27me3 was increased at the p11 promoter in CUS-exposed mice compared with control mice (100 $\pm 7 \%$ vs. $222 \pm 17 \%, p<0.001)$. Importantly, early-life EE significantly decreased the H3K27me3 level at the p11 promoter in CUS-exposed mice (222 $\pm 17 \%$ vs. $132 \pm 8 \%, p<0.001)$. Moreover, a significant effect of EE was observed in comparison with the control mice (100 $\pm 7 \%$ vs. $54 \pm 4 \%, p=0.006)$. 


\section{Discussion}

Early enrichment experience may promote offspring brain health and increase early mental development [28]. EE is already well known for its positive effects on depressionlike and anxiety-like behaviors in human and animal models. However, the mechanism of early EE's beneficial effect on adulthood depression has not been investigated. In the present study, EE prevented the depression-like behavior and increased corticosterone observed in a CUS model of depression. One of the underlying mechanisms of early-life EE may involve epigenetic modification of the hippocampal p11 gene promoter.

Our behavioral data demonstrate that early EE prevented the behavioral despair state induced by CUS during adulthood, suggesting that early EE improves the ability to cope with stress under an unpredictable stress situation, as in CUS. Moreover, exposure to EE during PND 21-55 exerted antidepressant-like effects similar to those of antidepressant drugs when animals were tested at PND 84. Our data demonstrate for the first time that the long-term effects of early EE resulted from increased p11 expression accompanied by alterations in histone modification within the $\mathrm{p} 11$ promoter.

In this experiment, CUS animals exhibited higher levels of stress-induced corticosterone secretion compared to control animals. This result is consistent with previous reports showing reduced body weight gain, hypercorticosteronemia, increased adrenal weight, and anxiety- and depression-like behaviors [29,30]. In previous study, mice exposed to chronic restraint stress exhibited reduced p11 expression in medial prefrontal cortex and depression-like behaviors [31]. In the results of the functional analysis of p11, p11 overexpression in neurons of the medial prefrontal cortex rescued depression-like behaviors induced by chronic stress, and further alleviated depression-like phenotypes exhibited in neuron-specific or global deleted mice of p11 [31]. They emphasized that p11 in neurons is a key molecule in chronic stress-induced depression. Consistent with previous studies, our study also showed that reduced p11 expression influenced CUS-induced behavior. To strengthen this point, further research is needed on the functional analysis of p11. We performed the FST to assess the depression-like behavior. Although many researchers use this model for behavioral despair tests, the FST is a more appropriate tool for screening antidepressant drugs [32]. Additional behavioral tests are needed, such as the sucrose preference test to measure anhedonia and the Morris water maze test to measure spatial memory.

In our experiment, CUS-induced depressive mice displayed significantly decreased acetylation of $\mathrm{H} 3(\mathrm{~K} 9$ and $\mathrm{K} 14)$ at the $\mathrm{p} 11$ promoter of the hippocampus with obviously increasing HDAC5 expression. In agreement with these results, Liu et al. reported that rats exposed to CUS exhibited significant decreases in acetylation of H3 (K9) and H4 (K12) with increasing HDAC5 in the hippocampus, which was linked to anxiety- and depression-like behavior [33]. Erburu et al. found that chronic social defeat stress induced a decrease in the acetylation levels of $\mathrm{H} 3$ and $\mathrm{H} 4$ at the BDNF promoter as well as an increase in nuclear HDAC5 expression [34]. Similarly, chronic variable stress resulted in decreased histone acetylation of $\mathrm{H} 3$ and $\mathrm{H} 4$ and increased expression of the HDAC5 protein, which was related to lower weight, a higher corticosterone level, higher adrenal weight, and lower sucrose preference [35]. These studies suggest that the hypoacetylation of histone induced by chronic stress may cause changes in chromatin structure and compaction and modulate transcription of a depression-related gene such as p11, as observed in the present study.

It is generally believed that an increase in HDACs would cause a decrease in the levels of histone acetylation, leading to gene silencing. Reduced HDAC expression would increase gene transcription [36]. Expression of HDAC5, but not of several other HDACs, was downregulated in the hippocampus of animals exposed to chronic stress that had been treated with antidepressant drugs $[37,38]$. Consistent with the present study, CUS increased HDAC5 expression in the rat hippocampus [33]. HDAC5 mRNA levels were increased in the peripheral leukocytes of drug-free depressive patients, and this increase was recovered by paroxetine treatment [39]. Moreover, HDAC5 was reported to epigenetically control behavioral adaptation to chronic emotional stimuli [40]. Based on these studies, we 
focused specifically on HDAC5 among the classes of HDACs. However, a weakness of the study was that the expression of other HDAC isoforms (HDAC1-11) was not examined. Thus, further studies on other HDAC isoforms associated with depression are needed to demonstrate the specificity of changes in HDAC5 expression.

Additionally, we observed significant changes in histone methylation of K4, a permissive methylation marker, and K27, a repressive methylation marker. Chronic stress regulation of histone methylation in the hippocampus has been investigated in several studies. Chronic social defeat stress produced a robust increase in H3K27 dimethylation at the BDNF promoter, whereas H3K9 dimethylation, another histone modification that is correlated with transcriptional repression, was not increased [37]. In that study, social defeat stress did not affect the dimethylation of $\mathrm{H} 3 \mathrm{~K} 4$, but chronic imipramine treatment was able to increase this modification in mice exposed to defeat stress [37]. In another study, chronic restraint stress increased global levels of $\mathrm{H} 3 \mathrm{~K} 9 \mathrm{me} 3$ and $\mathrm{H} 3 \mathrm{~K} 4 \mathrm{me} 3$ in the hippocampus, whereas global levels of H3K27me3 showed no effect [41]. Our study showed that CUS decreased H3K4me3 and increased H3K27me3 at the p11 promoter of the hippocampus. It appears that modes of histone methylation may differ based on methylation of specific gene promoters vs. global methylation. Further studies are necessary to understand the functional importance of these various modes of histone methylation in the hippocampus.

In the present study, early EE had a strong antidepressant effect in adulthood. Preclinical studies using animal models of depression have shown that EE reverses depression-like behavior and improves cognitive impairment by exposure to stress (i.e., early life stress, prenatal chronic stress, adult stress) $[25,42,43]$. EE markedly reversed a prolonged corticosterone secretion induced by prenatal stress [44]. EE has been shown to exert antidepressant effects by restoring reduced BDNF, nerve growth factor, neurogenesis, and synaptic plasticity induced by exposure to stress [45-47]. These effects on EE will have a significant impact on weakening the vulnerability on adult stress.

Studies on the effects of EE in the post-weaning period have mainly focused on providing enrichment after prenatal stressful experiences, and the effects of postnatal EE on resilience to adulthood stress have not been examined. Studies of positive postnatal experiences in rats have shown that postnatal maternal care has long-term consequences for behavior and stress responses among adults $[6,7,48,49]$. The mechanism of this action reportedly involved DNA methylation of the hippocampal glucocorticoid receptor promoter I . Adult offspring of mothers that exhibited high levels of licking and grooming showed increased hippocampal glucocorticoid receptor expression, more modest HPA responses, and lower anxiety compared with the offspring of mothers that exhibited low licking and grooming behaviors. As p11 expression is associated with depression-like states and antidepressant treatment responses, our findings show that postnatal EE's upregulation of p11 expression through histone modification of the p11 promoter may offer a potential strategy for the prevention of adult depression.

EE treatment in adult rodents induced epigenetic changes in DNA methylation. The offspring of parents exposed to an enriched cage environment during pregnancy exhibited significant reductions in global DNA methylation in the hippocampus and frontal cortex [50]. This finding is in line with a previous study demonstrating that EE reduced 5-hydroxymethylcytosine in the hippocampus, indicating a potential role for epigenetic markers such as DNA methylation [51]. The reduction in DNA methylation within a specific gene promoter implies an increase in the expression of that specific gene. Early-life EE may increase the expression of genes associated with the developmental programming of stress resilience by reducing DNA methylation. Moreover, exposure to EE has been shown to induce hippocampal structural changes by improving neural plasticity, as seen in increased numbers of dendritic branches and spines, enlargement of synapses, and increased neurogenesis [21]. This effect was due to increased BDNF expression via sustained histone modification of BDNF promoters (a significant increase in $\mathrm{H} 3 \mathrm{~K} 4 \mathrm{me} 3$ and significant decreases in $\mathrm{H} 3 \mathrm{~K} 9 \mathrm{me} 3$ and $\mathrm{H} 3 \mathrm{~K} 27 \mathrm{me} 3$ ) in the hippocampus [52]. 
Exposure to EE has been shown to elevate serotonin concentrations and BDNF expression in the hippocampus $[53,54]$. One study showed that serotonin increased the p11 level only if BDNF was present, suggesting that BDNF is required for serotonin-induced increases in p11 [17]. These findings support a role for $\mathrm{p} 11$ in the antidepressant action of BDNF induced by EE. While the current study focused on only one gene, further studies should investigate the effects of early EE on the epigenetic regulation of stress-related genes such as BDNF.

In the present study, both acetylation and methylation of histone $\mathrm{H} 3$ were altered at the p11 promoter during EE and CUS. These changes may be related to the interaction of HDAC5 with histone methyltransferases. As typical histone methyltransferases, G9a and EZH2 (specific to H3K27) and Set7/9 (specific to H3K4) should be further investigated. Moreover, it is important to show a dynamic interaction of G9a/EZH2/HDAC5 and Set7/9/HDAC5 at the promoter of p11 gene using chromatin immunoprecipitation (ChIP) assays. Further studies of current efforts are needed to provide evidence for histone acetylation and methylation-related regulation of the p11 gene.

In conclusion, the present study is the first to show prolonged exposure to early-life EE increased p11 expression through sustained chromatin regulation, which induced significant changes in histone acetylation and methylation in the hippocampus. This mechanism could partially explain interindividual difference in the stress response.

\section{Materials and Methods}

\subsection{Animals and Groups}

Pregnant C57BL/6J female mice (Daehan Biolink, Eumseong, Korea) arrived at the animal facility on the fifteenth day of pregnancy. Pregnant females were individually housed with sawdust until delivery. When parturition was observed, each dam and her offspring were carefully relocated to a standard cage. The offspring were weaned at postnatal day (PND) 21. Males are commonly used in animal experiments for depression. Data variability in females is large due to disturbing factors, such as the menstrual cycle [55]. All mice were maintained under standard laboratory conditions $\left(21^{\circ} \mathrm{C}, 12 / 12-\mathrm{h}\right.$ light/dark cycle, free access to food and water).

All male mice were randomly assigned to four groups: Control (control group), postnatal enriched environment (EE group), adulthood chronic unpredictable stress with no prior EE (CUS group), and postnatal EE with adulthood CUS (EE + CUS group) (Figure 1).

\subsection{Enriched Environment (EE)}

All EE animals (EE and EE + CUS group) were housed in EE cages $\left(26 \times 42 \times 18 \mathrm{~cm}^{3}\right)$ during PND 21-55, whereas other animals (control and CUS group) were housed in standard cages $\left(20 \times 26 \times 13 \mathrm{~cm}^{3}\right)$. In adulthood ( 8 weeks of age), all mice were housed in standard cages. The mice housed in EE cages (6-8 animals per cage) were provided with a variety of objects, such as running wheels, tunnels, small balls, and differently shaped blocks. EE cages were designed to promote neural activation, to enhance physical activity and cognition, and to provide somatosensory, visual, and motor stimulation [20]. In contrast, the control and CUS groups were housed in standard cages (6-8 animals per cage) without access to any objects.

\subsection{Chronic Unpredictable Stress (CUS)}

The CUS and EE + CUS groups were subjected to CUS for 4 weeks starting at 8 weeks of age. All mice were housed in standard cages $\left(20 \times 26 \times 13 \mathrm{~cm}^{3}, 6-8\right.$ animals per cage). The study used a previously described procedure [56], with slight modifications. The stressors were as follows: (1) 24-h empty cage; (2) 4-h restraint stress; (3) 4-h tilt cage (45 ); (4) 5-min cold swim ( $\left.4{ }^{\circ} \mathrm{C}\right)$; (5) 1-min tail nip; (6) 24-h water and food deprivation; (7) 24-h wet cage (100 g sawdust and $200 \mathrm{~mL}$ water mixed together). One stressor was randomly applied daily for one week; this was repeated for 4 weeks. The control and EE groups had no contact with the stressors. 


\subsection{Forced Swimming Test (FST)}

Twenty-four hours after the last CUS protocol, the mice were exposed to the FST with minor modifications [57]. The mice were placed individually in transparent plastic cylinders (height: 25, diameter: $10 \mathrm{~cm}$ ) that were filled to a depth of $12 \mathrm{~cm}$ with water $\left(23-25^{\circ} \mathrm{C}\right)$ for $7 \mathrm{~min}$. After a 2-min habituation period, the time spent immobile was recorded during the remaining $5 \mathrm{~min}$.

\subsection{Plasma Corticosterone Measurements}

After the FST, the mice were anesthetized rapidly by Alfaxan $(80 \mathrm{mg} / \mathrm{kg}$, i.p.; Jurox, NSW, Australia) and blood was quickly collected from the abdominal aorta. Plasma corticosterone levels were measured using an enzyme-linked immunosorbent assay kit (Enzo Life Sciences, Farmingdale, NY, USA) in accordance with the manufacturer's instructions.

\subsection{Measurement of $m R N A$ Levels by qRT-PCR}

The mice were anesthetized after the FST, and the whole brain was removed. The hippocampus was dissected from the brain, frozen in liquid nitrogen, and stored at $-80{ }^{\circ} \mathrm{C}$. RNA isolation, cDNA synthesis, and quantitative real-time polymerase chain reaction (qRT-PCR) were performed as described previously [38]. qRT-PCR was performed on a 7500 real-time PCR system (Applied Biosystems, Foster City, CA, USA). Glyceraldehyde3-phosphate dehydrogenase (GAPDH) was used as a housekeeping gene. The gene-specific primers (Table 1) for $\mathrm{p} 11, \mathrm{HDAC}$, and GAPDH were used under the following conditions: $95^{\circ} \mathrm{C}$ for $10 \mathrm{~min}$, followed by 40 cycles of $95^{\circ} \mathrm{C}$ for $15 \mathrm{~s}, 55^{\circ} \mathrm{C}$ for $35 \mathrm{~s}$, and $72{ }^{\circ} \mathrm{C}$ for $35 \mathrm{~s}$. The cycle threshold $(\mathrm{Ct})$ values were calculated automatically. Relative quantification was performed using the $2^{-\Delta \Delta \mathrm{Ct}}$ comparative $\mathrm{Ct}$ method, where $\Delta \mathrm{Ct}=\mathrm{Ct}_{\text {target gene }}-\mathrm{Ct}_{\mathrm{GAPDH}}$. The final value was expressed relative to the control group.

Table 1. List of primers used in this study.

\begin{tabular}{|c|c|c|}
\hline \multicolumn{3}{|c|}{ Primer Sequence $\left(5^{\prime}-3^{\prime}\right)$} \\
\hline \multicolumn{3}{|c|}{ qRT-PCR for mRNA } \\
\hline \multirow{2}{*}{$\mathrm{p} 11$ * } & Forward & TGCTCATGGAAAGGGAGTTC \\
\hline & Reverse & CCCCGCCACTATTGATAGAA \\
\hline \multirow{2}{*}{ HDAC5 \# } & Forward & CCATTGGAGATGTGGAATAC \\
\hline & Reverse & CAGTGGAGACAGATGTCCTT \\
\hline \multirow{2}{*}{$\mathrm{GAPDH}^{+}$} & Forward & AACAGCAACTCCCATTCTTC \\
\hline & Reverse & TGGTCCAGGGTTTCTTACTC \\
\hline \multicolumn{3}{|c|}{ qRT-PCR for histone modification } \\
\hline \multirow{2}{*}{ p11 promoter $\S$} & Forward & CGTTCCTCCTGCTTATCTAG \\
\hline & Reverse & GCTCTTAGTATTTCAGGGCA \\
\hline
\end{tabular}

${ }^{*}$ Mus musculus S100 calcium binding protein A10 (calpactin) (S100a10), mRNA; NCBI reference sequence: NM_009112.2. " Mus musculus histone deacetylase 5 (Hdac5), transcript variant 4, mRNA; NCBI reference sequence: NM_001284249.1. ${ }^{+}$Mus musculus glyceraldehyde-3-phosphate dehydrogenase, pseudogene 14 (Gapdhps14) on chromosome 8; NCBI reference sequence: NG_007829.2. \$ Mus musculus strain C57BL/6J chromosome 3, GRCm38.p4 C57BL/6J; NCBI reference sequence: NC_000069.6 (GenBank Assembly ID: GCF_000001635.24).

\subsection{Chromatin Immunoprecipitation (ChIP) Assays}

Chromatin was isolated from the hippocampus using a standard protocol (SimpleChIP ${ }^{\circledR}$ Plus Enzymatic Chromatic IP kit, Cell Signaling, Beverly, MA, USA) and immunoprecipitated with antibodies specific to histone $\mathrm{H3}$ acetylated at lysine 9 and 14 (AcH3; 06-599, Millipore, Billerica, MA, USA), histone $\mathrm{H} 3$ trimethylated at lysine 4 (H3K4me3; ab8580, Abcam, Cambridge, MA, USA), and histone H3 trimethylated at lysine 27 (H3K27me3; ab6002, Abcam Cambridge, MA, USA) using a Simple ChIP Plus Enzymatic Chromatic IP kit in accordance with the manufacturer's instructions. qRT-PCR was performed with primers specific to the p11 promoter region (Table 1) in the presence of SYBER Green (TOPreal $^{\text {TM }}$ qPCR 2X PreMIX, Enzynomics, Daejeon, Korea). To confirm antibody specificity, 
chromatin samples were immunoprecipitated with ChIP antibodies and normal rabbit IgG (\#2729; Cell Signaling, Beverly, MA, USA). qRT-PCR was performed on purified DNA using a control primer set (SimpleChIP ${ }^{\circledR}$ Mouse RPL30 Intron 2 Primers \#7015; Cell Signaling, Beverly, MA, USA) and p11 promoter primers (Figure S1). Ct values were normalized to the input DNA. Relative quantification was performed using the $2^{-\Delta \Delta \mathrm{Ct}}$ comparative $\mathrm{Ct}$ method, where $\Delta \mathrm{Ct}=\mathrm{Ct}_{\text {immunoprecipitation }}-\mathrm{Ct}_{\text {input }}$. The final value was expressed relative to the control group.

\subsection{Statistical Analysis}

All statistical analyses were performed using GraphPad Prism software (ver. 8.1, Graphpad Software Inc., La Jolla, CA, USA). To determine the main and interaction effects of EE and CUS, two-way ANOVA was performed. Tukey's multiple-comparison tests were used for post hoc comparisons. $p$-values $<0.05$ were considered to indicate statistical significance, and all data were presented as means \pm standard error of the mean (SEM).

Supplementary Materials: The following are available online at https:/ / www.mdpi.com/1422-006 7/22/4/1928/s1.

Author Contributions: Conceptualization, S.W.P. and J.G.L.; experiments and analysis, M.K.S., A.J.C., and D.-H.S.; writing—original draft, S.W.P.; writing—assistance, M.K.S. and J.G.L.; supervision, S.W.P. and J.G.L. All authors have read and agreed to the published version of the manuscript.

Funding: This research was supported by Basic Science Research Program through the National Research Foundation of Korea (NRF) funded by the Ministry of Education (NRF-2018R1D1A1B07049481 to J.G.L. and NRF-2020R1I1A3060731 to M.K.S.) and the Korea government (MIST) (NRF-2020R1A2C1010148 to S.W.P.).

Institutional Review Board Statement: All experimental procedures were conducted in accordance with guidelines for the care and use of laboratory animals for scientific purposes with approved protocols from the Committee for Animal Experimentation and the Institutional Animal Laboratory Review Board of Inje Medical College (approval no. 2016-053, approval date: 22 November 2016).

Informed Consent Statement: Not applicable.

Data Availability Statement: The data presented in this study are available on request from the corresponding author.

Conflicts of Interest: The authors declare no conflict of interest. A.J.C. is a researcher of Sumagen Ltd., in which she holds shares. The company had no role in the design, collection, analyses, or interpretation of data, the writing of the manuscript, or the decision to publish the results.

\section{Abbreviations}

$\begin{array}{ll}\text { AcH3 } & \text { Acetylation of histone H3 } \\ \text { ANOVA } & \text { Analysis of variance } \\ \text { BDNF } & \text { Brain-derived neurotropic factor } \\ \text { cDNA } & \text { Complementary deoxyribonucleic acid } \\ \text { ChIP } & \text { Chromatin immunoprecipitation } \\ \text { Ct } & \text { Cycle threshold } \\ \text { CUS } & \text { Chronic unpredictable stress } \\ \text { DNA } & \text { Deoxyribonucleic acid } \\ \text { EE } & \text { Enriched environment } \\ \text { EZH2 } & \text { Enhancer of zeste homolog 2 } \\ \text { FST } & \text { Forced swimming test } \\ \text { G9a } & \text { Euchromatic histone-lysine N-methyltransferase 2 (EHMT2) } \\ \text { GAPDH } & \text { Glyceraldehyde-3-phosphate dehydrogenase } \\ \text { H3 } & \text { Histone H3 } \\ \text { H3K4 } & \text { Histone H3 lysine 4 } \\ \text { H3K4me3 } & \text { Trimethylation of H3K4 }\end{array}$




$\begin{array}{ll}\text { H3K9 } & \text { Histone H3 lysine } 9 \\ \text { H3K9me3 } & \text { Trimethylation of H3K9 } \\ \text { H3K20 } & \text { Histone H3 lysine 20 } \\ \text { H3K27 } & \text { Histone H3 lysine 27 } \\ \text { H3K27me3 } & \text { Trimethylation of H3K27 } \\ \text { H3K36 } & \text { Histone H3 lysine 36 } \\ \text { H4 } & \text { Histone H4 } \\ \text { HATs } & \text { Histone acetyltransferases } \\ \text { HDAC5 } & \text { Histone deacetylase 5 } \\ \text { HDACs } & \text { Histone deacetylases } \\ \text { i.p. } & \text { Intraperitoneal } \\ \text { IP } & \text { Immunoprecipitation } \\ \text { K } & \text { Lysine } \\ \text { mRNA } & \text { Messenger RNA } \\ \text { PND } & \text { Postnatal day } \\ \text { qRT-PCR } & \text { Quantitative real-time polymerase chain reaction } \\ \text { RNA } & \text { Ribonucleic acid } \\ \text { RPL30 } & \text { Ribosomal protein L30 } \\ \text { SEM } & \text { Standard error of the mean } \\ \text { Set7/9 } & \text { SET domain-containing lysine N-methyltransferase 7 (SETD7) }\end{array}$

\section{References}

1. Bonanno, G.A. Loss, trauma, and human resilience: Have we underestimated the human capacity to thrive after extremely aversive events? Am. Psychol. 2004, 59, 20-28. [CrossRef]

2. Southwick, S.; Charney, D.S. The science of resilience: Implications for the prevention and treatment of depression. Science 2012, 338, 79-82. [CrossRef]

3. Murgatroyd, C.; Patchev, A.V.; Wu, Y.; Micale, V.; Bockmühl, Y.; Fischer, D.; Holsboer, F.; Wotjak, C.T.; Almeida, O.F.; Spengler, D. Dynamic DNA methylation programs persistent adverse effects of early-life stress. Nat. Neurosci. 2009, 12, 1559-1566. [CrossRef] [PubMed]

4. Lutz, P.E.; Turecki, G. DNA methylation and childhood maltreatment: From animal models to human studies. Neuroscience 2014, 264, 142-156. [CrossRef]

5. Lutz, P.E.; Almeida, D.; Flori, L.M.; Turecki, G. Childhood maltreatment and stress-related psychopathology: The epigenetic memory hypothesis. Curr. Pharm. Des. 2015, 21, 1413-1417. [CrossRef] [PubMed]

6. Liu, D.; Diorio, J.; Tannenbaum, B.; Caldji, C.; Francis, D.; Freedman, A.; Sharma, S.; Pearson, D.; Plotsky, P.M.; Meaney, M.J. Maternal care, hippocampal glucocorticoid receptors, and hypothalamic-pituitary-adrenal responses to stress. Science 1997, 277, 1659-1662. [CrossRef]

7. Weaver, I.C.; Cervoni, N.; Champagne, F.A.; D’Alessio, A.C.; Sharma, S.; Seckl, J.R.; Dymov, S.; Szyf, M.; Meaney, M.J. Epigenetic programming by maternal behavior. Nat. Neurosci. 2004, 7, 847-854. [CrossRef]

8. Borrelli, E.; Nestler, E.J.; Allis, C.D.; Sassone-Corsi, P. Decoding the epigenetic language of neuronal plasticity. Neuron 2008, 60 , 961-974. [CrossRef] [PubMed]

9. Choi, J.K.; Howe, L.J. Histone acetylation: Truth of consequences? Biochem. Cell Biol. 2009, 87, 139-150. [CrossRef] [PubMed]

10. Vogelauer, M.; Wu, J.; Suka, N.; Grunstein, M. Global histone acetylation and deacetylation in yeast. Nature 2000, 408, 495-498. [CrossRef]

11. de Ruijter, A.J.; van Gennip, A.H.; Caron, H.N.; Kemp, S.; van Kuilenburg, A.B. Histone deacetylases (HDACs): Characterization of the classical HDAC family. Biochem. J. 2003, 370, 737-749. [CrossRef] [PubMed]

12. Berger, S.L. The complex language of chromatin regulation during transcription. Nature 2007, 447, 407-412. [CrossRef]

13. Izzo, A.; Schneider, R. Chatting histone modifications in mammals. Brief Funct. Genom. 2010, 9, 429-443. [CrossRef]

14. Svenningsson, P.; Kim, Y.; Warner-Schmidt, J.; Oh, Y.S.; Greengard, P. p11 and its role in depression and therapeutic responses to antidepressants. Nat. Rev. Neurosci. 2013, 14, 673-680. [CrossRef]

15. Svenningsson, P.; Chergui, K.; Rachleff, I.; Flajolet, M.; Zhang, X.; El-Yacoubi, M.; Vaugeois, J.M.; Nomikos, G.G.; Greengard, P. Alterations in 5-HT1B receptor function by p11 in depression-like states. Science 2006, 311, 77-80. [CrossRef] [PubMed]

16. Warner-Schmidt, J.L.; Flajolet, M.; Maller, A.; Chen, E.Y.; Qi, H.; Svenningsson, P.; Greengard, P. Role of p11 in cellular and behavioral effects of 5-HT4 receptor stimulation. J. Neurosci. 2009, 29, 1937-1946. [CrossRef] [PubMed]

17. Warner-Schmidt, J.L.; Chen, E.Y.; Zhang, X.; Marshall, J.J.; Morozov, A.; Svenningsson, P.; Greengard, P. A role for p11 in the antidepressant action of brain-derived neurotrophic factor. Biol. Psychiatry 2010, 68, 528-535. [CrossRef] [PubMed]

18. Baroncelli, L.; Braschi, C.; Spolidoro, M.; Begenisic, T.; Sale, A.; Maffei, L. Nurturing brain plasticity: Impact of environmental enrichment. Cell Death Differ. 2010, 17, 1092-1103. [CrossRef]

19. Sale, A.; Berardi, N.; Maffei, L. Environment and brain plasticity: Towards an endogenous pharmacotherapy. Physiol. Rev. 2014, 94, 189-234. [CrossRef] 
20. Nithianantharajah, J.; Hannan, A.J. Enriched environments, experience-dependent plasticity and disorders of the nervous system. Nat. Rev. Neurosci. 2006, 7, 697-709. [CrossRef] [PubMed]

21. van Praag, H.; Kempermann, G.; Gage, F.H. Neural consequences of environmental enrichment. Nat. Rev. Neurosci. 2000, 1, 191-198. [CrossRef] [PubMed]

22. Baldini, S.; Restani, L.; Baroncelli, L.; Coltelli, M.; Franco, R.; Cenni, M.C.; Maffei, L.; Berardi, N. Enriched early life experiences reduce adult anxiety-like behavior in rats: A role for insulin-like growth factor 1. J. Neurosci. 2013, 33, 11715-11723. [CrossRef]

23. Mohammed, A.H.; Henriksson, B.G.; Söderström, S.; Ebendal, T.; Olsson, T.; Seckl, J.R. Environmental influences on the central nervous system and their implications for the aging rat. Behav. Brain Res. 1993, 57, 183-191. [CrossRef]

24. Olsson, T.; Mohammed, A.H.; Donaldson, L.F.; Henriksson, B.G.; Seckl, J.R. Glucocorticoid receptor and NGFI-A gene expression are induced in the hippocampus after environmental enrichment in adult rats. Brain Res. Mol. Brain Res. 1994, 23, 349-353. [CrossRef]

25. Yang, J.; Hou, C.; Ma, N.; Liu, J.; Zhang, Y.; Zhou, J.; Xu, L.; Li, L. Enriched environment treatment restores impaired hippocampal synaptic plasticity and cognitive deficits induced by prenatal chronic stress. Neurobiol. Learn Mem. 2007, 87, 257-263. [CrossRef]

26. Duman, R.S.; Li, N. A neurotrophic hypothesis of depression: Role of synaptogenesis in the actions of NMDA receptor antagonists. Philos. Trans. R. Soc. Lond. B 2012, 367, 2475-2484. [CrossRef] [PubMed]

27. Duman, R.S.; Monteggia, L.M. A neurotrophic model for stress-related mood disorders. Biol. Psychiatry 2006, 59, $1116-1127$. [CrossRef]

28. Tomporowski, P.D. Exercise and Cognition. Pediatr. Exerc. Sci. 2016, 28, 23-27. [CrossRef] [PubMed]

29. Hollis, F.; Isgor, C.; Kabbaj, M. The consequences of adolescent chronic unpredictable stress exposure on brain and behavior. Neuroscience 2013, 249, 232-241. [CrossRef]

30. Monteiro, S.; Roque, S.; de Sá-Calçada, D.; Sousa, N.; Correia-Neves, M.; Cerqueira, J.J. An efficient chronic unpredictable stress protocol to induce stress-related responses in C57BL/6 mice. Front. Psychiatry 2015, 6, 6. [CrossRef]

31. Seo, J.S.; Wei, J.; Qin, L.; Kim, Y.; Yan, Z.; Greengard, P. Cellular and molecular basis for stress-induced depression. Mol. Psychiatry 2017, 22, 1440-1447. [CrossRef] [PubMed]

32. Deussing, J.M. Animal models of depression. Drug Discov. Today Dis. Models 2006, 3, 375-383. [CrossRef]

33. Liu, D.; Qiu, H.M.; Fei, H.Z.; Hu, X.Y.; Xia, H.J.; Wang, L.J.; Qin, L.J.; Jiang, X.H.; Zhou, Q.X. Histone acetylation and expression of mono-aminergic transmitters synthetases involved in CUS-induced depressive rats. Exp. Biol. Med. 2014, 239, 330-336. [CrossRef] [PubMed]

34. Erburu, M.; Muñoz-Cobo, I.; Domínguez-Andrés, J.; Beltran, E.; Suzuki, T.; Mai, A.; Valente, S.; Puerta, E.; Tordera, R.M. Chronic stress and antidepressant induced changes in Hdac5 and Sirt2 affect synaptic plasticity. Eur. Neuropsychopharmacol. 2015, 25, 2036-2048. [CrossRef] [PubMed]

35. Ferland, C.L.; Schrader, L.A. Regulation of histone acetylation in the hippocampus of chronically stressed rats: A potential role of sirtuins. Neuroscience 2011, 174, 104-114. [CrossRef]

36. Gallinari, P.; Di Marco, S.; Jones, P.; Pallaoro, M.; Steinkühler, C. HDACs, histone deacetylation and gene transcription: From molecular biology to cancer therapeutics. Cell Res. 2007, 17, 195-211. [CrossRef]

37. Tsankova, N.M.; Berton, O.; Renthal, W.; Kumar, A.; Neve, R.L.; Nestler, E.J. Sustained hippocampal chromatin regulation in a mouse model of depression and antidepressant action. Nat. Neurosci. 2006, 9, 519-525. [CrossRef]

38. Seo, M.K.; Ly, N.N.; Lee, C.H.; Cho, H.Y.; Choi, C.M.; Nhu, L.H.; Lee, J.G.; Lee, B.J.; Kim, G.M.; Yoon, B.J.; et al. Early life stress increases stress vulnerability through BDNF gene epigenetic changes in the rat hippocampus. Neuropharmacology 2016, 105, 388-397. [CrossRef]

39. Iga, J.; Ueno, S.; Yamauchi, K.; Numata, S.; Kinouchi, S.; Tayoshi-Shibuya, S.; Song, H.; Ohmori, T. Altered HDAC5 and CREB mRNA expressions in the peripheral leukocytes of major depression. Prog. Neuropsychopharmacol. Biol. Psychiatry 2007, 31, 628-632. [CrossRef]

40. Renthal, W.; Maze, I.; Krishnan, V.; Covington, H.E., III; Xiao, G.; Kumar, A.; Russo, S.J.; Graham, A.; Tsankova, N.; Kippin, T.E.; et al. Histone deacetylase 5 epigenetically controls behavioral adaptations to chronic emotional stimuli. Neuron 2007, 56, 517-529. [CrossRef]

41. Hunter, R.G.; McCarthy, K.J.; Milne, T.A.; Pfaff, D.W.; McEwen, B.S. Regulation of hippocampal H3 histone methylation by acute and chronic stress. Proc. Natl. Acad. Sci. USA 2009, 106, 20912-20917. [CrossRef]

42. Cui, M.; Yang, Y.; Yang, J.; Zhang, J.; Han, H.; Ma, W.; Li, H.; Mao, R.; Xu, L.; Hao, W.; et al. Enriched environment experience overcomes the memory deficits and depressive-like behavior induced by early life stress. Neurosci. Lett. 2006, 404, $208-212$. [CrossRef]

43. Vega-Rivera, N.M.; Ortiz-López, L.; Gómez-Sánchez, A.; Oikawa-Sala, J.; Estrada-Camarena, E.M.; Ramírez-Rodríguez, G.B. The neurogenic effects of an enriched environment and its protection against the behavioral consequences of chronic mild stress persistent after enrichment cessation in six-month-old female Balb/C mice. Behav. Brain Res. 2016, 301, 72-83. [CrossRef] [PubMed]

44. Morley-Fletcher, S.; Rea, M.; Maccari, S.; Laviola, G. Environmental enrichment during adolescence reverses the effects of prenatal stress on play behaviour and HPA axis reactivity in rats. Eur. J. Neurosci. 2003, 18, 3367-3374. [CrossRef] 
45. Llorens-Martín, M.V.; Rueda, N.; Martínez-Cué, C.; Torres-Alemán, I.; Flórez, J.; Trejo, J.L. Both increases in immature dentate neuron number and decreases of immobility time in the forced swim test occurred in parallel after environmental enrichment of mice. Neuroscience 2007, 147, 631-638. [CrossRef]

46. Veena, J.; Srikumar, B.N.; Mahati, K.; Bhagya, V.; Raju, T.R.; Shankaranarayana Rao, B.S. Enriched environment restores hippocampal cell proliferation and ameliorates cognitive deficits in chronically stressed rats. J. Neurosci. Res. 2009, 87, 831-843. [CrossRef]

47. Llorens-Martín, M.; Tejeda, G.S.; Trejo, J.L. Antidepressant and proneurogenic influence of environmental enrichment in mice: Protective effects vs. recovery. Neuropsychopharmacology 2011, 36, 2460-2468. [CrossRef] [PubMed]

48. Caldji, C.; Tannenbaum, B.; Sharma, S.; Francis, D.; Plotsky, P.M.; Meaney, M.J. Maternal care during infancy regulates the development of neural systems mediating the expression of behavioral fearfulness in adulthood in the rat. Proc. Natl. Acad. Sci. USA 1998, 95, 5335-5340. [CrossRef] [PubMed]

49. Francis, D.D.; Diorio, J.; Liu, D.; Meaney, M.J. Nongenomic transmission across generations in maternal behavior and stress responses in the rat. Science 1999, 286, 1155-1158. [CrossRef]

50. Mychasiuk, R.; Zahir, S.; Schmold, N.; Ilnytskyy, S.; Kovalchuk, O.; Gibb, R. Parental enrichment and offspring development: Modifications to brain, behavior and the epigenome. Behav. Brain Res. 2012, 228, 294-298. [CrossRef]

51. Irier, H.; Street, R.C.; Dave, R.; Lin, L.; Cai, C.; Davis, T.H.; Yao, B.; Cheng, Y.; Jin, P. Environmental Enrichment Modulates 5-hydroxymethylcytosine Dynamics in Hippocampus. Genomics 2014, 104, 376-382. [CrossRef]

52. Kuzumaki, N.; Ikegami, D.; Tamura, R.; Hareyama, N.; Imai, S.; Narita, M.; Torigoe, K.; Niikura, K.; Takeshima, H.; Ando, T.; et al. Hippocampal epigenetic modification at the brain-derived neurotrophic factor gene induced by an enriched environment. Hippocampus 2011, 21, 127-132. [CrossRef] [PubMed]

53. Brenes, J.C.; Padilla, M.; Fornaguera, J. A detailed analysis of open-field habituation and behavioral and neurochemical antidepressant-like effects in postweaning enriched rats. Behav. Brain Res. 2009, 197, 125-137. [CrossRef]

54. Jha, S.; Dong, B.; Sakata, K. Enriched environment treatment reverses depression-like behavior and restores reduced hippocampal neurogenesis and protein levels of brain-derived neurotrophic factor in mice lacking its expression through promoter IV. Transl. Psychiatry 2011, 1, e40. [CrossRef] [PubMed]

55. Planchez, B.; Surget, A.; Belzung, C. Animal models of major depression: Drawbacks and challenges. J. Neural Transm. 2019, 126, 383-1408. [CrossRef]

56. Shen, J.; Li, Y.; Qu, C.; Xu, L.; Sun, H.; Zhang, J. The enriched environment ameliorates chronic unpredictable mild stress-induced depressive-like behaviors and cognitive impairment by activating the SIRT1/miR-134 signaling pathway in hippocampus. J. Affect Disord. 2019, 248, 81-90. [CrossRef]

57. Porsolt, R.D.; Bertin, A.; Jalfre, M. Behavioral despair in mice: A primary screening test for antidepressants. Arch. Int. Pharmacodyn. Ther. 1977, 229, 327-336. 